\title{
Clinical and pathological study of a case of congenital muscular dystrophy
}

\author{
S. S. GUBbAY, JOHN N. WALTON, AND G. W. PEARCE \\ From the Departments of Neurology and Pathology, Newcastle General Hospital, \\ Newcastle upon Tyne
}

The classification of disorders giving rise to generalized hypotonia of the skeletal musculature in infancy has been discussed previously by Walton (1956, 1957) who suggested that these cases can be separated into three categories, namely, infantile spinal muscular atrophy, symptomatic hypotonia, and benign congenital hypotonia. Congenital muscular dystrophy is one of the least common causes of symptomatic hypotonia in infancy and a review of the literature by Short (1963) revealed seven reported cases with necropsy information, to which a further case presenting with congenital hypotonia was added. Banker, Victor, and Adams (1957) have described the clinico-pathological findings in two male sibs with congenital muscular dystrophy: the initial clinical picture in one of them was of arthrogryposis multiplex congenita, whereas the other had hypotonic flaccid weakness without contracture at birth. Greenfield, Cornman, and Shy (1958) listed congenital or early infantile muscular dystrophy of Batten amongst the different conditions of muscle which can produce the clinical syndrome of weakness and hypotonia at birth or in the early weeks of life.

The following case report with biochemical, histological, and electron microscopic findings is of a $5 \frac{1}{2}$-year-old child with congenital hypotonia and weakness who also showed multiple contractures giving the appearance of arthrogryposis multiplex and in whom muscle biopsy has shown the histological changes of progressive muscular dystrophy. It is thought worthy of record because of the apparent rarity of this condition.

\section{CASE REPORT}

H.T., a girl, was born at full term by normal delivery on 5 October 1960 at the General Hospital, Bishop Auckland, with a birth weight of $6 \mathrm{lb} .7 \mathrm{oz}$. Her mother, who was 29 years of age at the time, had mild hyperemesis for the first seven months of gestation and in the last few days before delivery her blood pressure became elevated. The foetal movements which were observed during pregnancy were thought to be unremarkable.
This was the mother's second pregnancy, the first being $\stackrel{\widetilde{D}}{\circ}$ complicated by toxaemia, and surgical induction three weeks before term resulted in the stillbirth of a $3 \mathrm{lb}$. $12 \mathrm{oz}$. female infant following prolapse of a non-pulsating. umbilical cord. No obvious abnormality was apparent $\vec{H}$ on external examination of the stillborn child. There ${ }_{\mathscr{S}}$ have been no subsequent pregnancies.

The onset of respiration in the patient was immediate after delivery although for the next two days she wasi said to have been very 'chesty'. Within the first week it. was noticed that she held her hands clenched in a fully pronated position and there was a paucity of movemento in both upper limbs. These characteristics persisted apd were associated with a generalized floppiness of the $\mathrm{S}$ limbs and head and bilateral talipes deformities of the feet. By the age of 6 months she had achieved onty precarious head control and had an ever-open mouth which gave the impression of mental defect. At ofe 3 year it was evident that there was gross retardation of motor development, although judging by her genemalbehaviour and attempts at speech mental developmente seemed normal. She was unable to roll over or sit un-क supported and could not raise her arms above her head, although she was able to put her hands to her moutho when eating. At this stage the child was seen by one of us (J.N.W.) who found a generalized muscle weakness andō hypotonia with marked weakness and wasting of proxi-๊ mal muscles but no fasciculation of the tongue and no $\propto$ definite weakness of the chest wall musculature. All the $\overrightarrow{\vec{P}}$ deep tendon reflexes excepting the knee jerks were $\frac{O}{3}$ absent. The differential diagnosis entertained at this stage was between a non-progressive spinal muscular atrophy, congenital muscular dystrophy, and benign congenital hypotonia.

The patient was admitted to the Babies' Hospita[, Royal Victoria Infirmary, in May 1962 for further:investigation. The haemoglobin was $11.8 \mathrm{~g} . / 100 \mathrm{ml}$; the total W.B.C. and differential counts and E.S.R. were normal. The serum albumin was $4.6 \mathrm{~g} . / 100 \mathrm{ml}$. and globulin $1 \cdot 7 / \mathrm{g} .100 \mathrm{ml}$., and electrophoresis of the serum proteins revealed a double beta band. T-waves were some-은 what flattened in V5 and V6 in the electrocardiogram but $>$ a chest radiograph was normal with no evidence of cardiaco enlargement. The serum aldolase level was raised to $29 \cdot 7 \mathrm{~N}$ units (Bruns), the S.G.O.T. was 58 units per ml. per min-O ute, and the serum creatine kinase level 12.6 units according $N$ to the method of Pearce, Pennington, and Walton (1964) N 


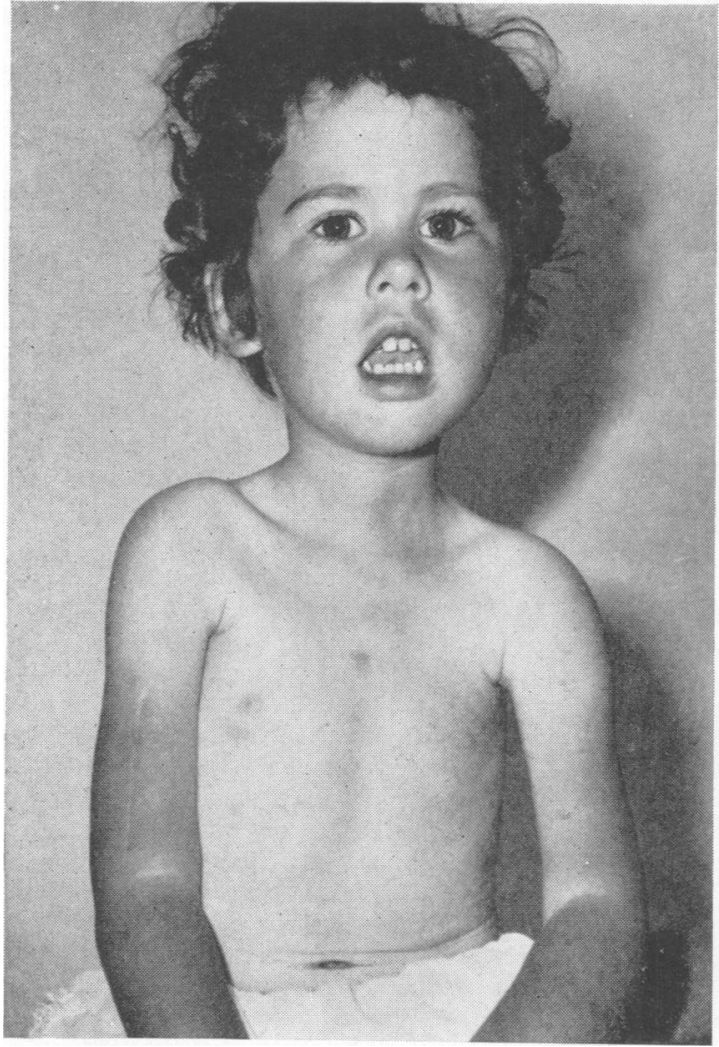

FIG. 1 The patient; note the open mouth, the atrophy of proximal muscles and contractures of biceps brachii.

(normal upper limit 4.0 units). Electromyography of the right quadriceps muscle using a concentric needle electrode revealed no spontaneous activity and motor unit discharges appearing on volition were of low amplitude but did not appear otherwise abnormal. Exploration of the right upper arm and examination of the biceps, brachialis, and triceps through a single incision over the lateral aspect of the right arm was undertaken on 24 May 1962 when the muscles were noted to be tough and fibrous and to consist of pale, firm tissue with no resemblance to normal muscle. A biopsy was taken from the biceps and the histological findings are described below.

The child was examined in detail at the age of 3 years and 5 months on 4 March 1964. She was cheerful and cooperative and weighed $28 \frac{1}{2} \mathrm{lb}$. with a height of 40 inches. Her speech was normal for her age and she appeared of normal intelligence. Her head flopped forward on to the trunk when unsupported and she tended to hold her mouth open (Fig. 1). There was moderate bilateral facial weakness and she was unable to roll, sit up on her own, or stand. Widespread and moderately severe contractures of limb muscles had developed, especially of the biceps brachii (Fig. 2), long finger and toe flexors, hamstrings, quadriceps and of the tendons of

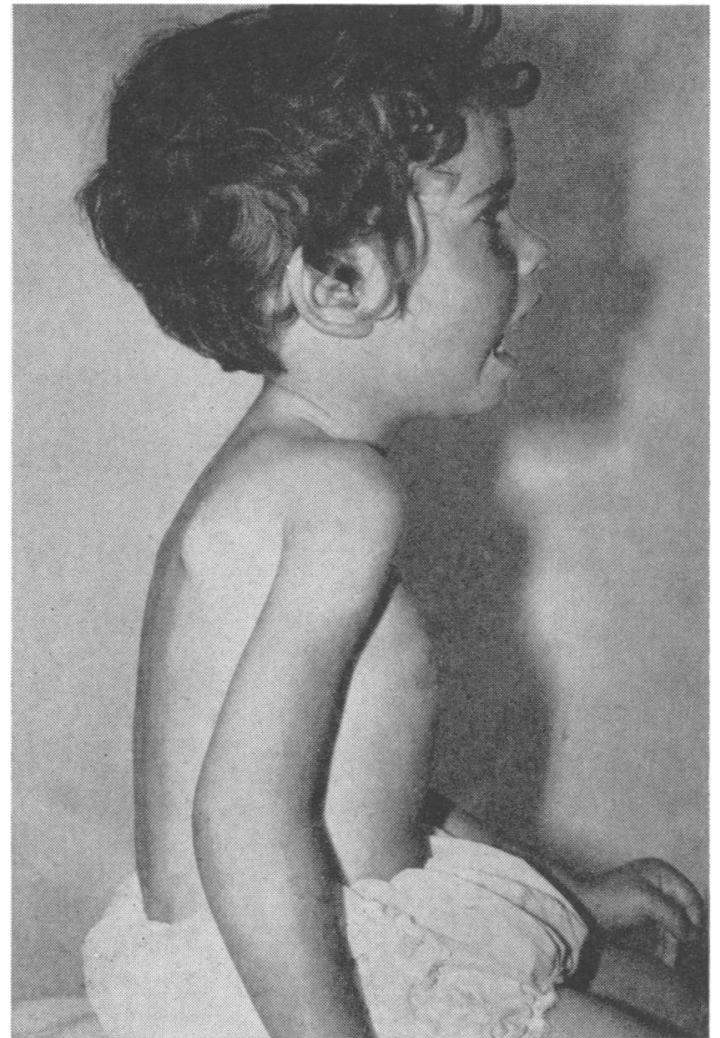

FIG. 2 Lateral view demonstrating atrophy of upper limb muscles and contracture of biceps.

Achilles (Fig. 3). Gross restriction of movement was noted at both shoulders and both hip joints. The entire limb musculature was of tough and fibrous texture, particularly in the calves, and this had been noticed by the parents since birth. There was moderate wasting of the sternomastoids and shoulder girdle muscles with winging of the scapulae, marked wasting of biceps, triceps, and deltoids, and slight wasting of forearm muscles; the lower limbs appeared of normal bulk. Moderate generalized muscular hypotonia was evident. All muscle groups were very weak and, where applicable, were mostly unable to overcome gravity. The deep tendon reflexes were all abolished and the plantar responses flexor. Sensation was intact and examination of the cardiovascular and respiratory systems and abdomen was normal. The child has been re-examined at six-monthly intervals and was last seen on 15 March 1966. Muscular weakness has remained virtually unchanged; contractures have increased slightly and while she can sit unaided she is still unable to stand.

\section{HISTOLOGICAL METHODS AND FINDINGS}

For electron microscopy, three samples of muscle from the biopsy of the right biceps brachii were fixed in 


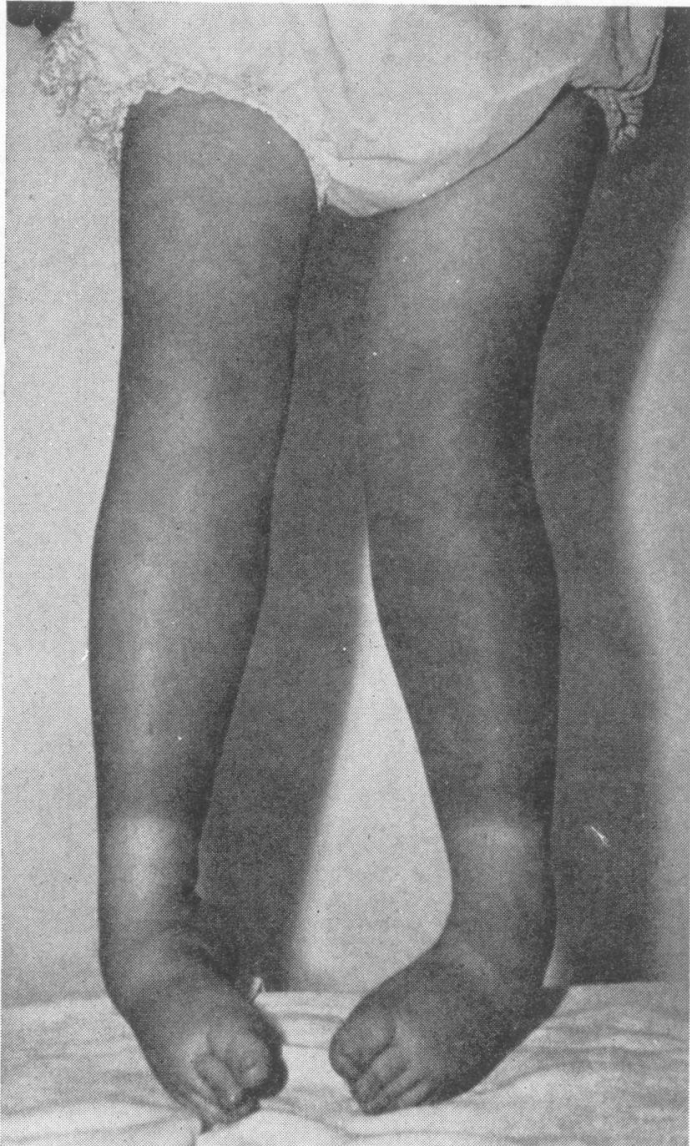

FIG. 3 Contractures in the lower extremities.

Palade's (1952) osmic fixative for two hours, stained with $1 \%$ phosphotungstic acid in absolute alchohol, and embedded in prepolymerized methacrylate. Sections were cut on an L.K.B. Ultrotome and examined with a Siemens Elmiskop 1 electron microscope. The remainder of the biopsy was fixed in formol calcium and embedded in paraffin wax for light microscopy.

LIGHT MICROSCOPY The muscle fibres were everywhere embedded in dense connective tissue; they showed great diversity of size from considerable hypertrophy to extreme atrophy (Fig. 4). In most areas the fibres were mixed together without regard to size but a few areas comprised mainly atrophic fibres. However, there was no evidence of grouped atrophy indicating denervation. Localized areas of muscle fibre necrosis and phagocytosis were present and a group of phagocytes was seen within the substance of one fibre when sectioned transversely (Fig. 5).

Many fibres were found to be rounded in outline when cut transversely and centrally situated nuclei were common. Most of the muscle fibres were affected by the disease process but cross-striations were commonly $\underset{\mathbb{D}}{Z}$ well preserved. Not infrequently the longitudinal stria- $\stackrel{\Phi}{=}$ tions formed by the individual myofibrils did not have o visible transverse banding and their parallel arrangement $\stackrel{?}{?}$ was often in disarray. Hyaline or floccular degeneration $\widehat{\theta}$ was seen in some fibres and involved the diameter in 0 whole or in part. Vacuolation was also seen occasionally (Fig. 6). Two small areas of sarcoplasmic basophilia $\stackrel{5}{=}$. were present in the sections and both were surrounding two or three large vesicular nuclei containing prominent $:$ nucleoli. However, such regenerative activity was $\overrightarrow{\vec{F}}$ scanty. Blood vessels showed no specific abnormality. $\stackrel{\rho}{+}$ One small collection of lymphocytes was present but other cells of inflammatory type were not seen. The $\bar{D}$ histological picture was characteristic of progressive $\frac{\bar{\rho}}{\partial}$. muscular dystrophy at a moderately advanced stage of $\underset{D}{ }$ the disease process.

ELECTRON MICROSCOPY The appearance of the myo- $\vec{\circ}$ fibrils varied from normality to fusion into a homo- $\vec{\overrightarrow{ }}$ geneous mass. The constituent myofilaments of the $\vec{\omega}$ myofibrils were commonly seen to be lost, particularly at the periphery, with thinning of the myofibril. Fusion of myofibrils was seen in many atrophic fibres so that the array of I and A bands was no longer discernible, 0 but even in these severely damaged areas discrete myofilaments, especially myosin filaments, could still bㄱㅇㅇ seen. The interfibrillar space was obliterated in the areas but its previous site and the approximate boundas 은 ies of the fibrils could sometimes be determined by the presence of short rows of empty vesicles which wege chiefly the dilated remnants of the longitudinal sarco $\mathbb{\infty}$ tubular system. In these areas of coagulation necrosid $\stackrel{\mathbb{D}}{\stackrel{D}{~}}$ mitochondria, glycogen, and other structures usual could not be identified. In many sections the sarcolemm was structurally normal while the external collagen laye $\vec{e}$ was greatly proliferated and apparently fused with the $\mathscr{D}$ periphery of the muscle fibre (Fig. 7). However, this case also showed that the sarcolemma could be interrupted or even absent when the underlying sarcomeres were relatively intact or showing minor changes only (Fig. 8).

Collagen was not observed actually within the sub- $\frac{2}{\mathbb{D}}$ stance of the muscle fibres but it sometimes appeared $\varrho$ to erode the fibre superficially from the periphery $\overrightarrow{\overrightarrow{0}}$ causing a reduction in diameter of the fibre. Electron 3 microscopical examination of this material has not shown actual macrophage or fibroblastic activity within a muscle fibre but only at its edges even though light microscopy of one muscle fibre cut transversely did show numerous centrally situated macrophages (Fig. 5); however, this section probably passed through the extremity of an area of segmental necrosis within a fibre. Vesicles of various sizes were commonly present $\delta$ immediately beneath the sarcolemma or near to the periphery of a fibre whose myofibrils had fused; many 을 of these vesicles were interpreted as dilated sarcotubular elements but some were probably mitochondria which $\frac{D}{2}$ had lost their internal cristae (Fig. 9). Such vesicles were commonly found immediately below the sarcolemma of of dystrophic fibres but where the sarcolemma was defective or not clearly visible because of adherent 


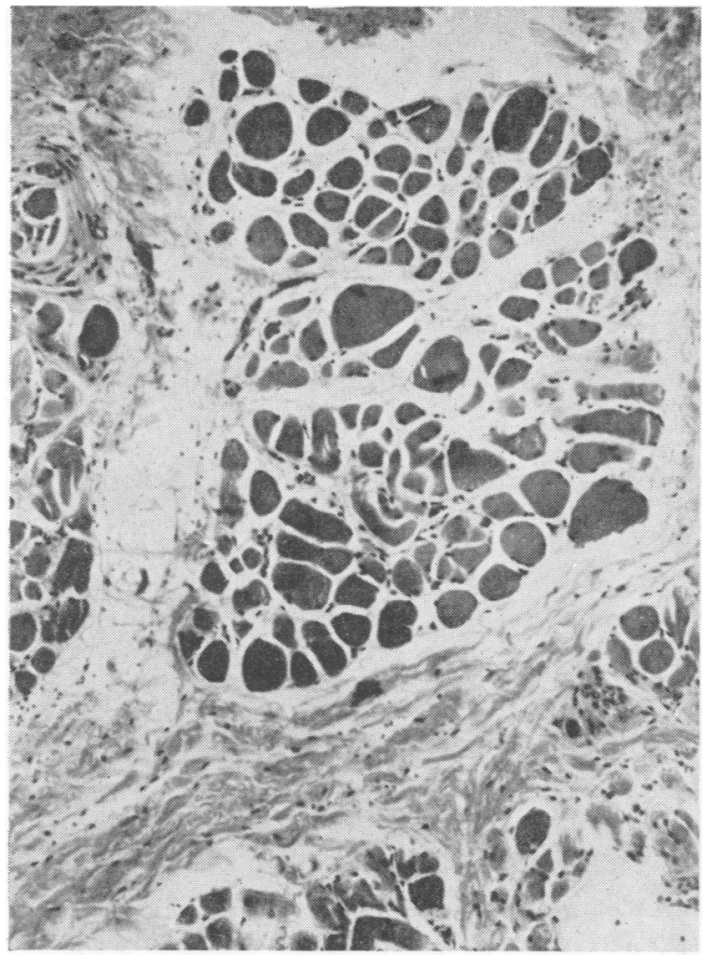

FIG. 4.

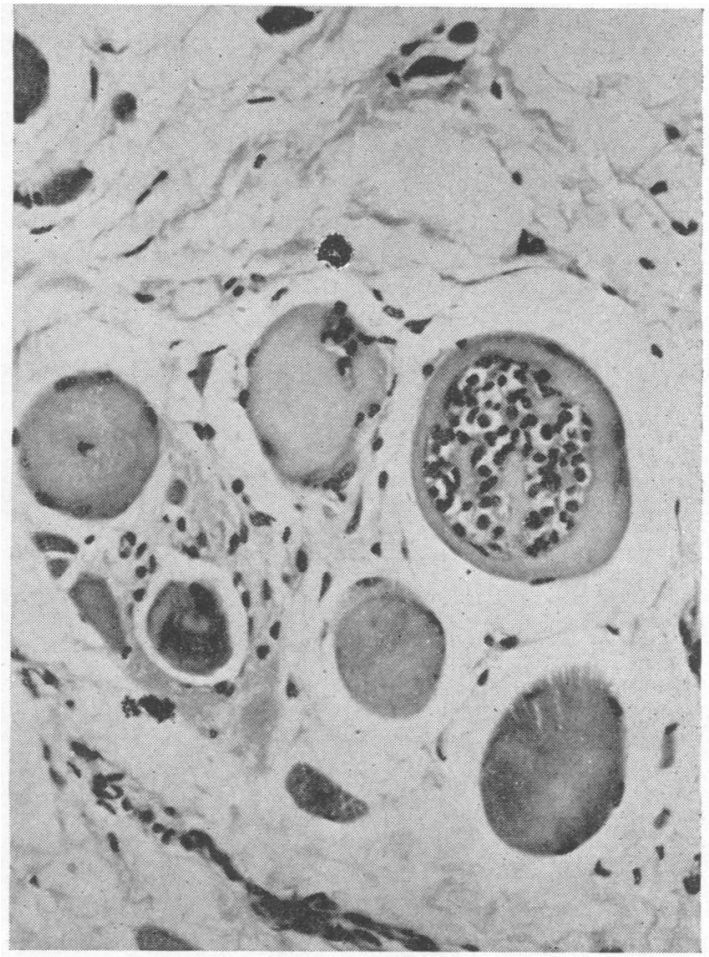

FIG. 5 .

FIG. 4. Fasciculi of muscle fibres are embedded in a mass of interfascicular connective tissue. Individual muscle fibres show marked variations in size and shape, fibre splitting, and separation by strands of connective tissue. Haematoxylin and eosin $\times 100$.

FIG. 5. One muscle fibre shows necrosis with central phagocytosis of necrotic sarcoplasm. This uncommon appearance is probably explained by the fact that the transverse section passes through the extremity of an area of segmental necrosis and phagocytosis. Haematoxylin and eosin $\times 256$.

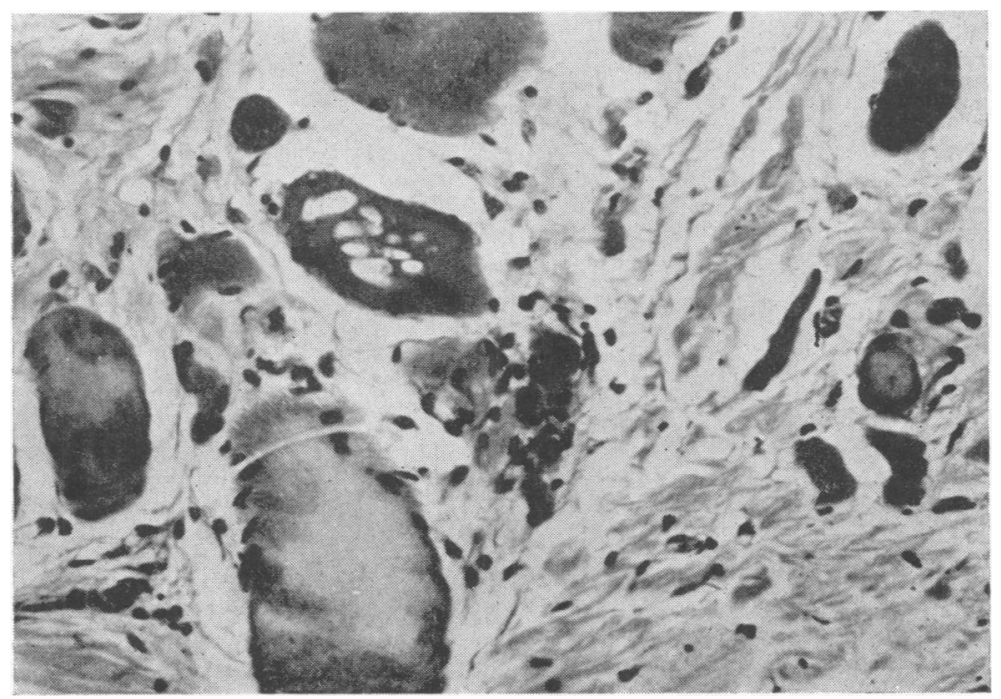

FIG. 6. Muscle fibres showing varying degrees of necrosis and fragmentation lie within proliferated connective tissue. One fibre shows vacuolar degeneration and another is undergoing phagocytosis. Haematoxylin and eosin $\times 256$. 


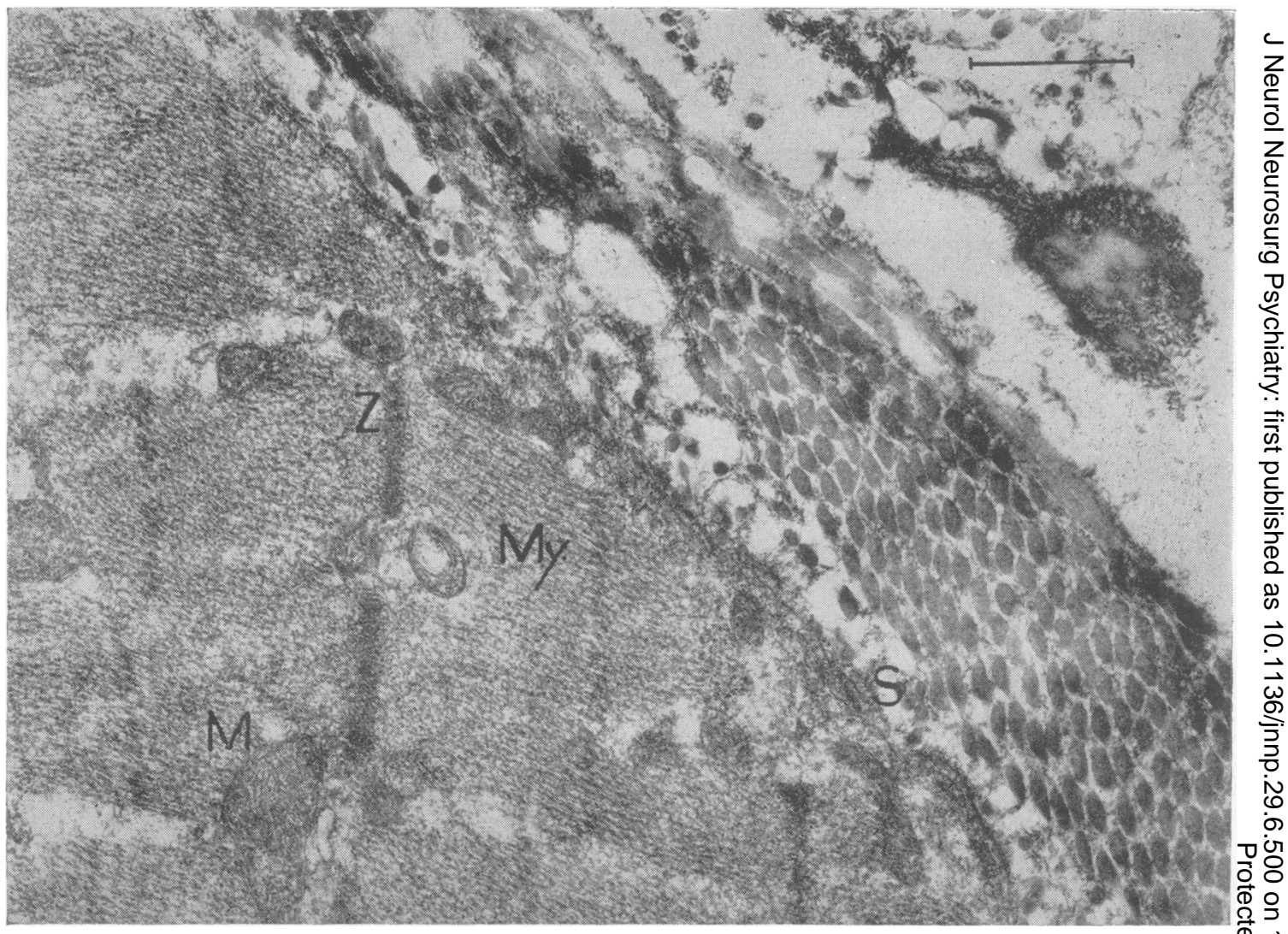

FIG. 7. An electron micrograph showing a relatively normal muscle fibre; immediately outside the intact sarcolemma is ® dense mass of collagen. $\times 27,000 .(Z=Z$ line, $M y=$ myofibril, $M=$ mitochondria, $S=$ sarcolemma $), i-1=1 \mu$.

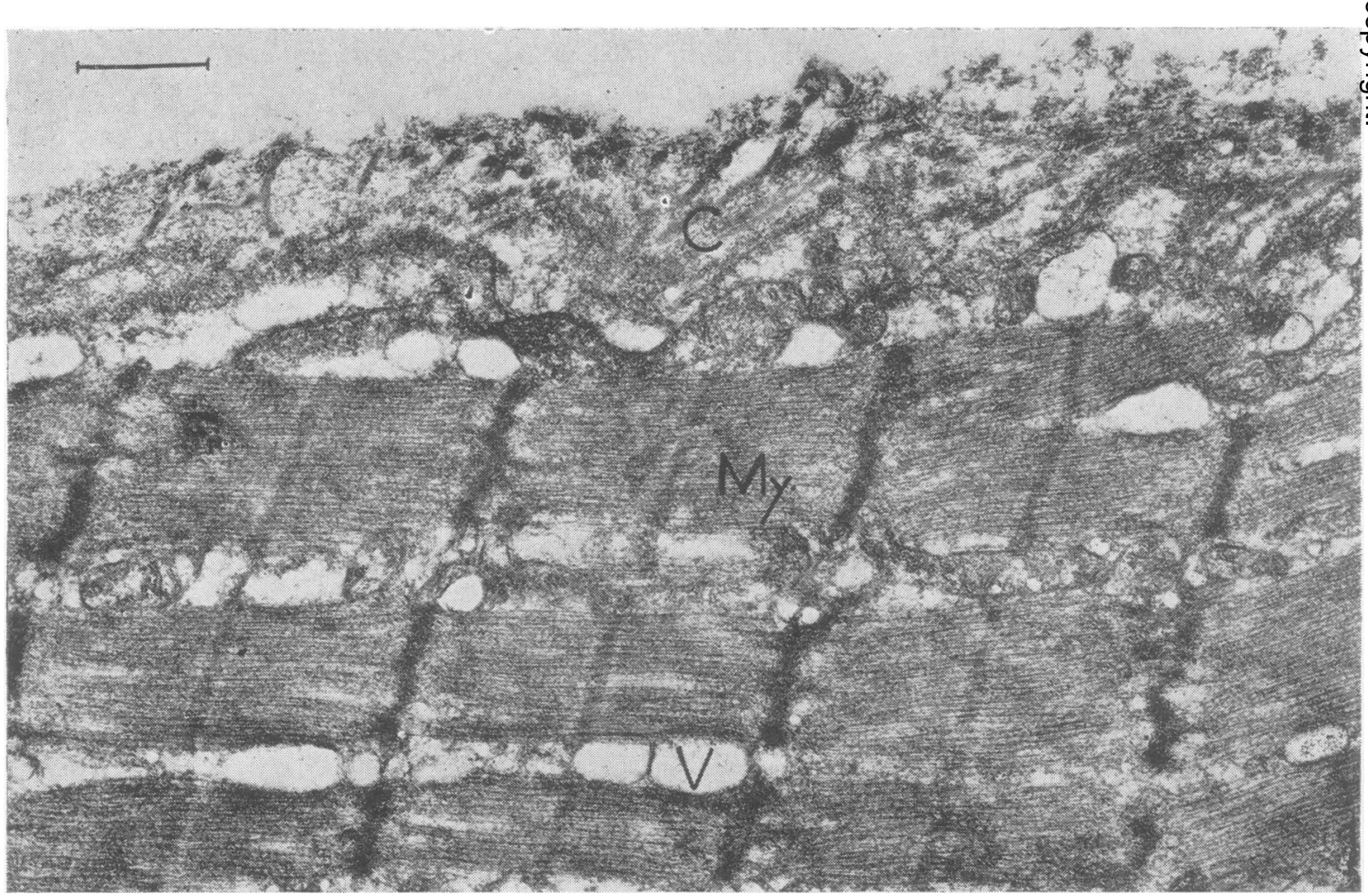
응 $\frac{\mathbb{1}}{3}$ 츨.

FIG. 8. An electron micrograph showing relatively normal muscle apart from some dilated tubules, but the sarcolemma is not visible throughout and the external collagen is dense, proliferated and adherent. $\times 19,500 .(C=$ collagen, V=vesicle.) 


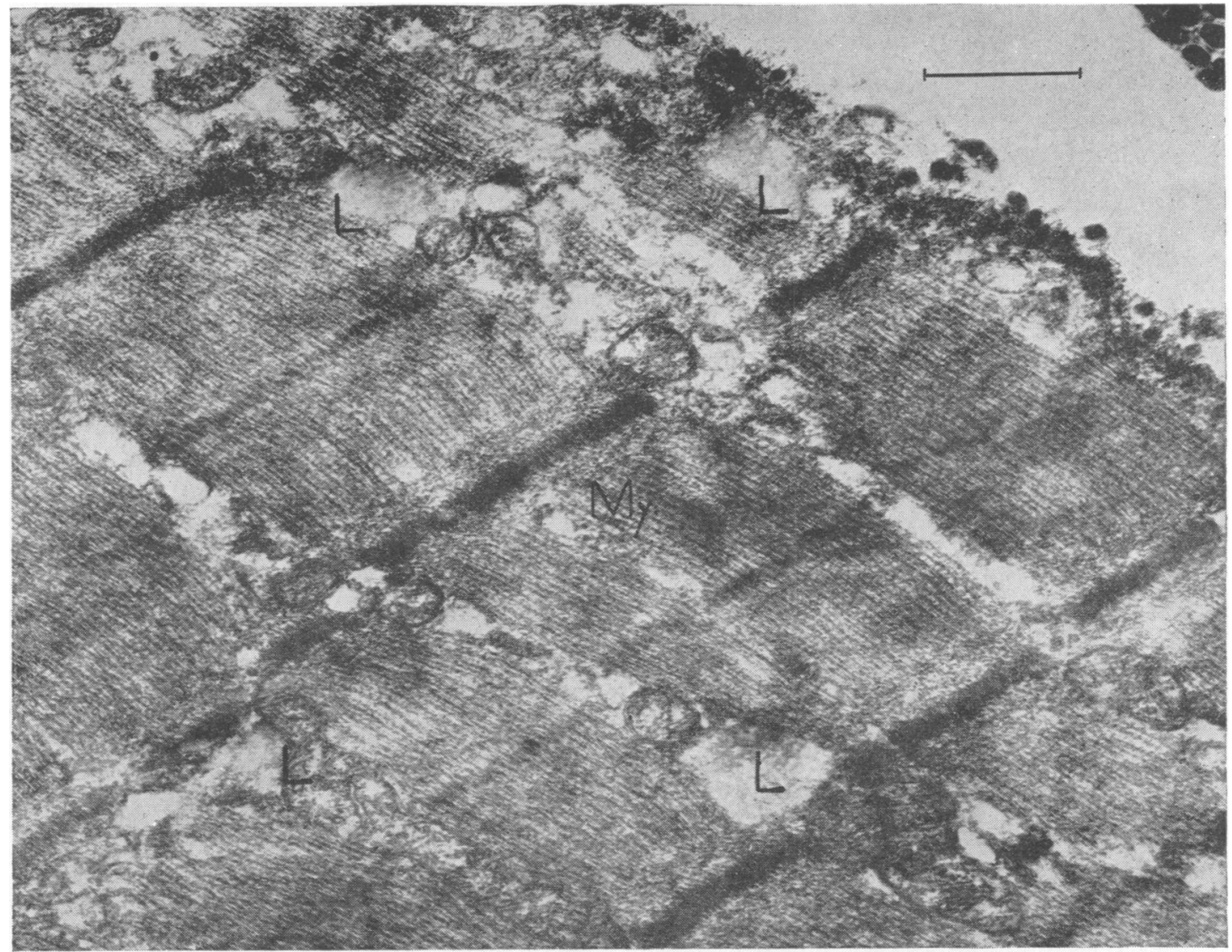

FIG. 9. An electron micrograph showing four lipid bodies lying between the myofibrils; the sarcolemma cannot be seen. $\times$ 26,100. ( $L=$ lipid body, $M y=$ myofibril.)

collagen it may be postulated that some at least could have arisen from fibroblastic or phagocytic sources external to the muscle fibre. However, direct cellular evidence to support this suggestion is lacking and it seems unlikely. Small indentations into the periphery of a dystrophic fibre have been seen which appear to carry in collagenous fibres from the exterior but vesicular structures have not regularly been seen in relation to these indentations.

Nuclei commonly showed crenation of the nuclear membrane and an intense coarse granularity which seems likely to correspond with the hyperchromatic appearance of nuclei found with light microscopy. Collections of fine granules were sometimes concentrated immediately internal to the nuclear membrane.

\section{DISCUSSION}

The clinico-pathological findings and the serum enzyme studies in this patient confirm the diagnosis of congenital muscular dystrophy, and other possible causes of infantile muscular hypotonia and weakness have been excluded. This patient showed none of the clinical or histological features of central core disease or nemaline myopathy.

Batten (1910) in his classification of the myopathies included a 'simple atrophic type' which began at birth or in infancy, was characterized by generalized smallness of bulk, hypotonia, and weakness of muscles, and which was gradually progressive with the formation of muscular contractures. Histological evidence of muscular dystrophy in children with congenital hypotonia has been recorded by various authors (Lereboullet and Baudouin, 1909; Councilman and Dunn, 1911; Haushalter, 1920; Turner, 1949; Banker et al., 1957; Lewis and Besant, 1962; O'Brien, 1962; Short, 1963). A pathological process in muscle which appeared to be dystrophic has been described in some cases of arthrogryposis multiplex congenita by Ullrich (1930), Middleton (1934), Stoeber (1938), Gilmour (1946), and Banker et al. (1957). 


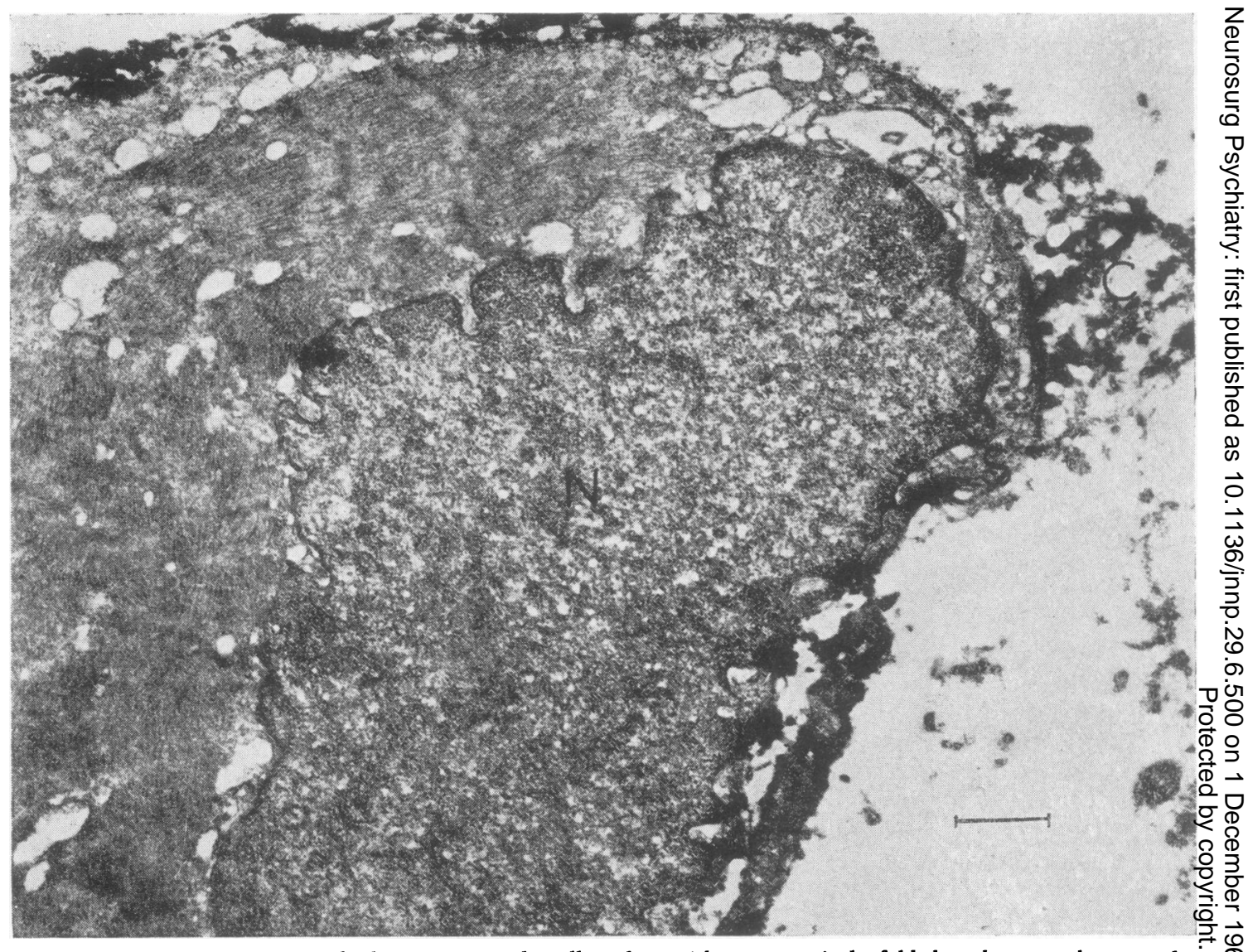

FIG. 10. An electron micrograph showing a muscle cell nucleus with an extensively folded nuclear membrane and an abnormally granular internal structure. A concentration of fine granules is found immediately under several areas of the folded nuclear membrane. The myofibrils are in disarray and numerous dilated tubules are present. The sarcolemma is defective in parts and slight collagen proliferation is present externally. $\times 16,500 . \quad(N=$ nucleus.)

In retrospect it is unfortunate that a necropsy examination was not performed on the stillborn elder sibling of the child described in this report, as the demonstration of a similar disease process might have given further support to the view expressed by Short (1963) that this disease entity may well show an autosomal recessive pattern of inheritance. Roberts (1929) described a congenital deformity in lambs due to a dystrophic muscular disease which was inherited as a simple autosomal recessive factor.

The reason why enzymes leak from a diseased muscle fibre into the blood stream is unknown but it is widely assumed that this leak may depend upon a defect in the muscle fibre membrane. Such a defect would explain the raised serum aldolase and creatine kinase levels found in this and in other varieties of dystrophy. However, previous electron microscopical studies by several workers (see
Pearce, 1964) have demonstrated that in most forms $\frac{\circ}{\mathbb{D}}$ of muscular dystrophy the sarcolemma is often remarkably resistant to structural change in spite of internal damage to the myofilaments and a moderate degree of collagen proliferation outside the fibre. The absence of morphological change in the sarcolemma even at electron microscopical level does not necessarily imply normal function, nor does it exclude the possibility that enzyme molecules may yet diffuse to an abnormal degree through the membrane. However, our findings in this case demonstrate that defects in the sarcolemma or even its apparent absence can be observed in a muscle fibre even when severe sarcomere damage $\frac{D}{O}$ is not present but when the external collagen is substantially proliferated. The external collagen $N$ proliferation appears to be a process occurring early $N$ in this congenital form of muscular dystrophy, and, 
together with widespread fusion of the myofibrils, it presumably accounts for the striking contractures. Electron microscopy of this collagenous material demonstrates that not only is it present in substantial amount but it may fuse with and possibly damage the sarcolemma before definite or relatively slight internal architectural alteration in the muscle fibres is seen. It may be suggested that the interruption or absence of the sarcolemma in these sections could be an artefact due to loss of the membrane during embedding or the preparation of sections. We can only say that similar changes have not been observed by us in normal material similarly treated and only very rarely in many sections of biopsies taken from patients with muscular dystrophy of the Duchenne type.

Our knowledge of the detailed submicroscopic pathology of muscle fibre atrophy and necrosis and of connective tissue proliferation is incomplete. In our descriptions of this material emphasis has been placed upon the loss and/or homogenization of myofilaments, myofibrils and mitochondria, disruption and loss of the sarcolemma, and the collagenous proliferation which seems to be fused to the exterior of the fibre but does not directly invade its interior. A system of vacuoles without definite internal structure is often found congregated at the edge of damaged fibres. The origin of these vacuoles requires elucidation but the great majority, if not all, appear to have arisen in the muscle fibre itself and are most likely to be the remnants of dilated longitudinal sarcotubular elements.

Electronmicroscopy of this material has notshown evidence of fibroblastic invasion and proliferation within the substance of a muscle fibre except at its extreme periphery where the sarcolemma appears to have been damaged. Light microscopy shows that areas of segmental necrosis and phagocytosis which not infrequently interrupt the continuity of muscle fibres may be associated with local fibrosis; however, we have not seen in electron microscopic sections collagenous invasion of any part other than the periphery of a dystrophic muscle fibre. Collagen proliferation thus exists as a phenomenon restricted entirely to the surface of the fibre. Electron microscopy of the proliferated collagen shows that most of the collagen fibrils lie in groups and are external and usually parallel to the sarcolemma; only rarely do the collagen fibrils lie obliquely to the fibre and these are then few in number. The limitations of electron microscopy and the difficulties of sampling error as well as those inherent in the interpretation of early changes mean that many more observations are required upon such cases before the significance of the pathological changes can be elucidated. The connective tissue proliferation observed in this case was certainly much greater than that generally observed in cases of muscular dystrophy of the Duchenne type, and muscular contractures were more striking clinically at an early stage of the disease than in patients with other forms of muscular dystrophy showing a comparable degree of muscular weakness. We are therefore impressed by the changes seen in the connective tissue in this rare condition of congenital muscular dystrophy and by the apparent damage to the sarcolemma, but many more observations will be required before we can understand their mode of production or assess the part which they play in the disease process. However, we do not wish to suggest that the collagenous proliferation necessarily plays an aetiological role in the disease process as the changes observed in the muscle fibres themselves (degeneration, necrosis, phagocytosis, abortive regeneration) are sufficient in our view to indicate that the disease is primarily due to a dystrophic process involving the muscle fibres themselves. Nevertheless, this form of congenital muscular dystrophy plainly differs in several important respects, both clinically and pathologically, from other varieties of the disease.

\section{SUMMARY}

We describe the case of a child with congenital muscular hypotonia and weakness who also showed progressive multiple contractures in profoundly weakened limb muscles. A muscle biopsy revealed changes similar in appearance to those of progressive muscular dystrophy and alterations in serum enzyme activity were consistent with a dystrophic process. It is concluded that this patient is suffering from the rare condition of congenital muscular dystrophy, giving rise to a clinical picture resembling arthrogryposis multiplex congenita.

We are grateful to Mr. J. Stewart, Miss M. Jenkinson, and Miss A. Brown for histological work and photography. This work was aided by research grants from the Muscular Dystrophy Associations of America, Inc., the Muscular Dystrophy Association of Canada and the Muscular Dystrophy Group of Great Britain.

\section{REFERENCES}

Banker, B. Q., Victor, M., and Adams, R. D. (1957). Arthrogryposis multiplex due to congenital muscular dystrophy. Brain, 80, 319-334.

Batten, F. E. (1910). The myopathies or muscular dystrophies. Quart. J. Med., 3, 313-328.

Councilman, W. T., and Dunn, C. H. (1911). Myatonia: congenita ; A report of a case with autopsy. Amer. J. Dis. Child., 2, 340355.

Gilmour, J. R. (1946). Amyoplasia congenita. J. Path. Bact., 58, 675685. 
Greenfield, J. G., Cornman, T., and Shy, G. M. (1958). The prognostic value of the muscle biopsy in the 'floppy infant'. Brain, 81, $461-484$.

Haushalter, P. (1920). Sur la myatonie congénitale (Maladie d'Oppenheim). Arch. Méd. Enf., 23, 133-144.

Lereboullet, M. M., and Baudouin, A. (1909). Un cas de myatonie congénitale avec autopsie. Bull. Soc. méd. Hóp. Paris, 3 ser., 27, $1162-1166$.

Lewis, A. J. and Besant, D. F. (1962). Muscular dystrophy in infancy: Report of two cases in siblings with diaphragmatic weakness. J. Pediat., 60, 376-384.

Middleton, D. S. (1934). Studies on prenatal lesions of striated muscle as a cause of congenital deformity. I. Congenital tibial kyphosis. II. Congenital high shoulder. III. Myodystrophia foetalis deformans. Edinb. med. J., 41, 401-442.

O'Brien, M. D. (1962). An infantile muscular dystrophy: Report of a case with autopsy findings. Guy's Hosp. Rep., 111, 98-106.

Palade, G. E. (1952). Study of fixation for electron microscopy, $J$. exp. Med., 95, 285.

Pearce, G. W. (1964). Tissue culture and electron microscopy in muscle disease. In Disorders of Voluntary Muscle, edited by J. N. Walton, pp. 220-254. Churchill, London.
Pearce, J. M. S., Pennington, R. J., and Walton, J. N. (1964). Serum enzyme studies in muscle disease. Part II-Serum creatine kinase, activity in muscular dystrophy and in other myopathic and neuropathic disorders. J. Neurol. Neurosurg. Psychiat., 27, 96-99.

Pennington, R. J. (1964). Biochemical aspects of muscle disease. In Disorders of Voluntary Muscle, edited by J. N. Walton, pp. 255-274. Churchill, London.

Roberts, J. A. F. (1929). The inheritance of a lethal muscle contracture in the sheep. J. Genet., 21, 57-69.

Short, J. K. (1963). Congenital muscular dystrophy: A case report with autopsy findings. Neurology (Minneap.), 13, 526-530.

Stoeber, E. (1938). ('Tber atonisch-sklerotische Muskeldystrophie (Typ Ulbrich). $Z$. Kinderheilk., 60, 279-284.

Turner, J. W. A. (1949). On amyotonia congenita. Brain, 72, 25-34.

Ullrich, O. (1930). Kongenitale, atonisch-sklerotische Muskeldystrophie, ein weiterer Typus der heredodegenerativen Erkrankungen des neuromuskulären Systems. Z. ges. Neurol. Psychiat., 126, 171-201.

Walton, J. N. (1957). The amyotonia congenita syndrome. Proc. roy. Soc. Med., 50, 301-308. 